\section{ELECTRONIC CONDUCTION IN MOLTEN KBr-K SOLUTIONS}

\author{
G. M. Haarberg and J. J. Egan \\ Brookhaven National Laboratory \\ Upton, NY 11973
}

The electronic conductivity of molten $\mathrm{KBr}-\mathrm{K}$ solutions was determined as a function of the activity of potassium at various temperatures by using the Wagner polarization technique. The diffusion coefficient of electrons was obtained from potential step measurements. The concentration of defects in the sait was calculated as a function of the $K$ activity by applying a thermodynamic model.

It was shiown by Bredig and coworkers (1) that dissolution of potassium in molten potassium halides gives rise to an increase in the total electrical conductivity. The excess conductivity, which is caused by formation of electrons upon metal dissolution, increases with increasing concentration of dissolved K. Direct conductivity measurements do not allow for an accurate study of the electronic conductivity at low contents of $K$. The Wagner polarization method was developed for the study of electronic conduction in solid electrolytes (2). This method, which yields directly the electronic conductivity as a function of the metal activity, was successfully applied by Egan and coworkers $(3,4)$ to study electronic conduction of molten sodium halides equilibrated with sodium.

Cells of the following type are set up

$$
\mathrm{Fe}(\mathrm{s})|\mathrm{KBr}(\ell)| \mathrm{K} \cdot \mathrm{Bi}(\ell)_{\mathrm{X}_{\mathrm{K}}}=0.04
$$

where the $\mathrm{K}-\mathrm{Bi}(\ell)$ alloy serves as a reference electrode with known activity of potassium and the iron electrode serves as an inert electron conductor electrode. The Fe electrode is made negative by applying potentials across the cell. Ionic conduction is suppressed when the applied potentials are lower than the decomposition potential of the salt. There is no movement of ions and the applied potential is used to increase the activity of $\mathrm{K}$ at the negative electrode. The current through the cell is due to the concentration gradient of electrons. The steady state current is measured as a function of the applied potential and the electronic conductivity can be calculated by the following equation which was given by Wagner (2)

$$
x_{c}=G \frac{d[I]}{d E}
$$

where $G$ is the cell constant and $I$ is the steady state current of cell (I).

The experimental cell is shown in Figure 1. The salt and the reference alloy ( 4 mole $\% \mathrm{~K}$ ) are contained in a tantalum crucibli. The $\mathrm{Fe}$ electrode is placed inside a sapphire capillary ( $4.2 \mathrm{~cm}$ long, $3 \mathrm{~mm}$ id). A vacuum-tight seal formed between iron and sapphire prevents the evaporation of $K$. The cell constant is determined by the geometry of the sapphire capiliary. An alumina tube with a K-Bi alloy contains an accurately known amount of $\mathrm{Bi}$. This electrode is used to determine the composition of the $\mathrm{K} \cdot \mathrm{Bi}$ alloy in the tantalum cup by coulometric titration of $\mathrm{K}$ between the two alloys.

\section{FEB DE92 008056 1900}

The steady stalkcurrent versus potential dara were fitted to an exponential equation using a least square computer program (see ref. (3)). Figure 2 shows experimental curtent vs. potential data at $800^{\circ} \mathrm{C}$ as well as the fitted exponential curve. The derivatives of the curves are used to obtain the electronic conductivity as a function of the applied potential according to Eq. (1). Since the applied potential corresponds to a certain activity of. $\mathrm{K}$ at the negative electrode, the electronic conductivity can be determined as a function of the activity of $\mathrm{K}$ in the salt using

$$
a_{K}=\exp \frac{\left(E-E^{\text {ret }}\right)}{R T}
$$

where $E^{\text {ret }}$ is the potential of the $\mathrm{K}$-Bi electrode versus pure $K$ taken from literature data $(5)$

The diffusion coefficient of electrons was determined from potential step measurements on cell (I). When a potential is applied a certain concentration of electrons is produced at the negative iron electrode. These electrons diffuse toward the reference electrode according to Fick's second law. By solving the necessary equations the following relation is obtained $(4,6)$

$$
D=\frac{1 \ell^{2}}{3(\mathrm{Q}-\mathrm{It})}
$$

where $\ell$ is the length of the sapphire capillary. By measuring the total number of coulombs (Q) passed through the cell until steady state is reached the diffusion coefficient of electrons (D) can be determined.

The dissolution of $\mathrm{K}$ in molten $\mathrm{KBr}$ leads to formation of F-centers and electrons. At high $K$ activities the presence of associated F-centers (dimers and trimers) is considered. A previously developed thermodynamic model $(3,4)$ was used to calculate the concentration of defects as a function of the activity of $\mathrm{K}$ in $\mathrm{KBr}$.

\section{REFERENCES}

1. M. A. Bredig, "Mixtures of Metais with Molten Salts," in Molten Salt Chemistry, M. Blander, Editor, p. 365, Interscience, New York, 1964.

2. C. Wagner, Proc. CITCE I, 361 (1957)

3. G. M. Haarberg, K. S. Osen, J. J. Egan, H. Heyer, W Freyland, Ber. Bunsenges. Phys. Chem. 92,139 (1988).

4. G. M. Haarberg, K. S. Osen, R. J. Heus, J. J. Egan, J. Electrochem. Soc. 137, 2777 (1990)

5. A. Petric, A. D. Pelton, M. L. Saboungi. J. Phys. F: Met. Phys. 18, 1473 (1988)

6. J. Cranck, The Mathematics of Diffusion, 2nd. Editor, Oxford University Press Fi: :iouse, London (1975).

The support of the Division of Chemical Sciences, United Stoies Department of, Energy, Washington, DC under contract No. DE-AC0276CH00016 is gratefully acknowledged. 

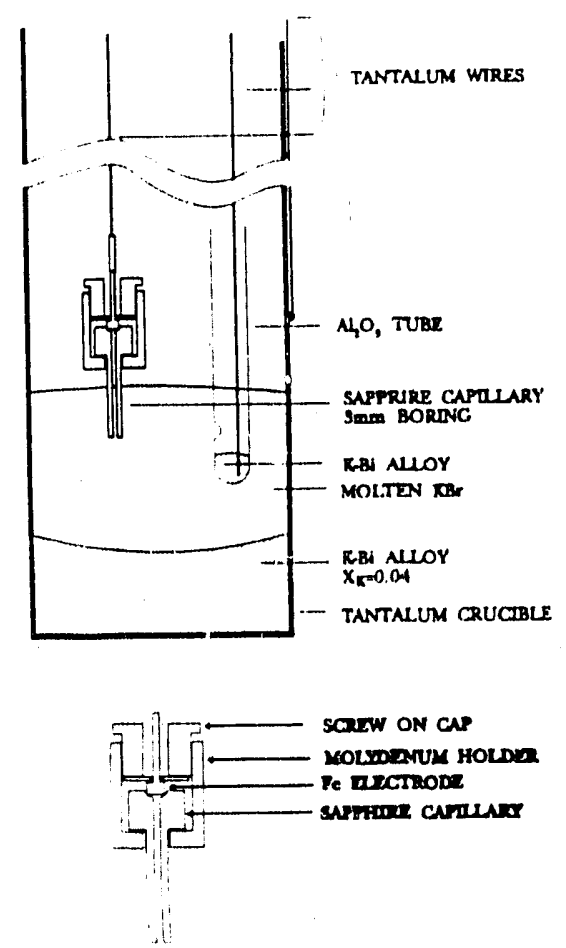

Figure 1. The experimental cell and details of the sapphire capillary.

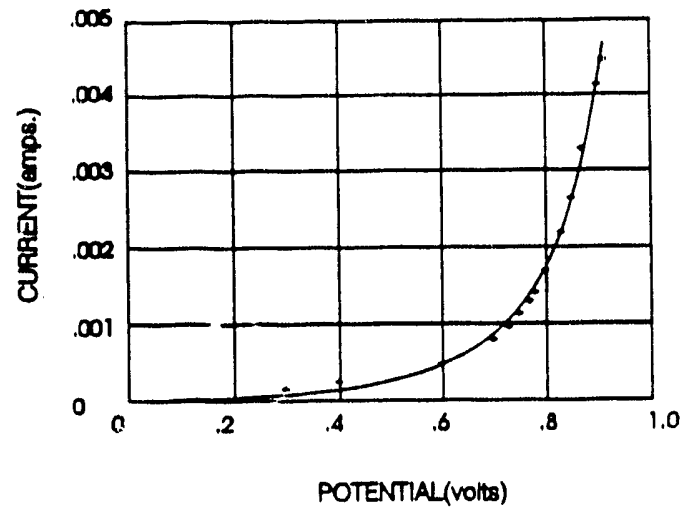

Figure 2. Current versus potential at $800^{\circ} \mathrm{C}$ for cell (I). 

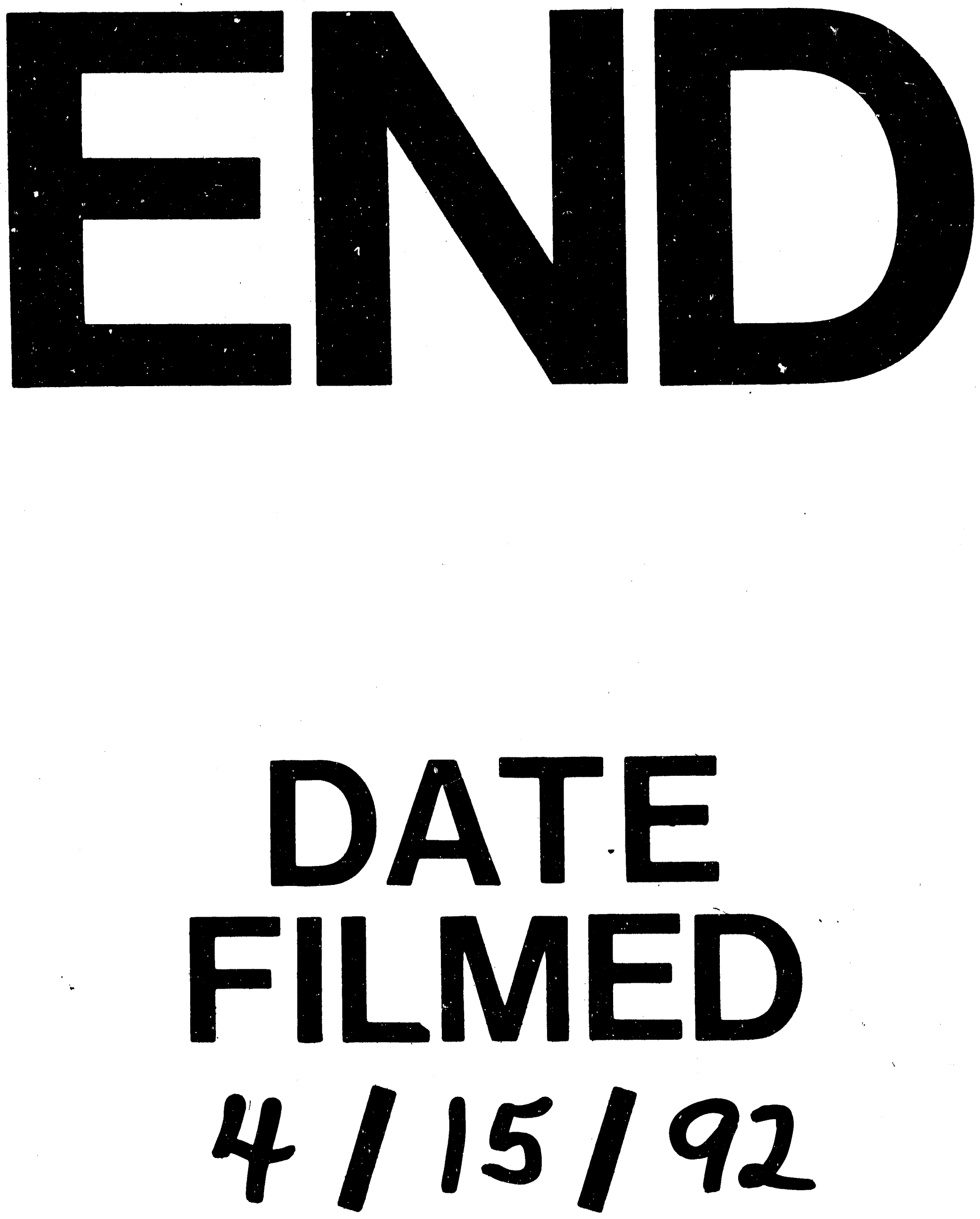
